\title{
DEMOCRACIA ARGUMENTATIVA \\ COMO REQUISITO ESSENCIAL \\ DO CUMPRIMENTO DO IDEAL DEMOCRÁTICO
}

\section{Ileide Sampaio de Sousa}

Mestranda em Direito (UFC). Bolsista da CAPES. Especialista em Direito Processual (FA7). Advogada.

ileidesampaio@yahoo.com.br

Sumário: Introdução. 1."Democracia Processual" e as variâncias do "jogo democrático". 2. A "Ética Discursiva" e o "Dialoguismo": da democracia de seguidores à democracia dos feitores. Considerações Finais. Referências.

Resumo: Este artigo tem como intuito analisar a perspectiva de Jürgen Habermas sobre a Democracia Processual, seus novos paradigmas de estabelecimento de uma razão consensual e a necessária vinculação do Direito, das "regras do jogo" à realidade social, ao "Jogo Democrático".

Palavras-chave: Democracia; Poder; "Regras do Jogo"; Heidegger; Habermas.

\section{INTRODUÇÃO}

Não jogamos porque há jogos, mas o inverso: há jogos porque jogamos [....]. (HEIDEGGER, 2009, p. 332).

[....] o paradigma jurídico da democracia constitucional: o jogo, mas também as regras do jogo democrático; o projeto democrático, mas também o método e as formas de democracia. (FERRAJOLI, 2006, p.431).

Democracia parece um jogo indecifrável. O fato de ser objeto da história da humanidade já seria razão suficiente para justificação de sua fluidez de conteúdo. A análise do "jogo da vida” de Heidegger auxiliará na perspectiva de que o projeto democrático não foi alcançado, porque é um projeto em construção, assim como o homem.

Contudo, a tese de que a Democracia é um ideal que deve ser abandonado pelo simples fato de ter sido, até hoje, inalcançável, não servirá 
como resposta à análise habermasiana de uma Democracia dialogal, que insira a fundamentalidade dessa esfera do Estado na realidade social. Para pontuar a importância da "Teoria da Ação Comunicativa" (NEVES, 2006, p.33) de Habermas iniciamos este artigo com uma simples história ilustrativa que assinala a evolução da participação do povo no desenvolvimento do modelo democrático:

Ouvem-se gritos de todos os lados. O povo foi chamado, não se sabe quando, nem por quem, mas foi. Cada um dos jogadores, em suas jogadas, defende um discurso. O povo aplaude, vaia. Aos poucos a multidão aquieta-se e começa a assistir ao compasso sonolento dos jogadores. O nome do jogo é "Democracia". Começou como regras dos deuses, depois, uma Igreja o quis aprisionar aos seus ditames. Depois, senhores burgueses tomaram conta de tudo e criaram efetivamente a Democracia Representativa. O jogo mudou e trouxe um problema: caberia ao povo apenas as bancadas da observação: agora outros estariam no comando. Nesse "novo" jogo democrático apostamos nas regras e nos jogadores e fechamos os olhos para o próximo modelo. O jogo é frio. Não há espaços para filosofias absolutistas, nem para relativismos axiológicos. A vida pede urgência na correspondência com o padrão que vive e com a aspiração que sonha. Aquele povo já não sabe mais que jogo se joga, se de fato estão jogando e se querem jogar.

A história agora desdobra-se. Entra em cena e senta-se à mesa outro homem. Muitos lhe chamam "filósofo" por sempre questionar a todas as teses já aceitas. Ele entra na reunião e atreve-se a pedir uma cadeira mais próxima para a observação. Ele não sabia, mas lá estava seu nome. Seu representante era pálido, e, assim como aquele jogo, nada o atraía. Olhando e entreolhando percebeu que nada era fixo, as regras serviam de justificativas e justificações diversas, teve então que transcender: ergue-se daquele assento e toma a palavra. Naquele momento, sua visão de mundo começou a mudar e o jogo teve que dar uma pausa em sua marcha irrefletida.

A mudança não estava prevista naquela reunião dos representantes do jogo. Então, aquele filósofo propôs, ao menos, o poder de escolher outros representantes com o decorrer do tempo e com base em sua avaliação. Era a mais nova transcendência. E a ela o filósofo chamou: o votar. Só que o tempo é terrível, e o poder aliançou-se com desejos e interesses outros. O filósofo viu-se com uma arma fracassada. Ele então propõe novas medidas: deixe-me fazer as regras. Exijo o exercício do referendo, plebiscito e da iniciativa popular. A esse novo transcender foi the dado um nome mais pomposo: era a Democracia Semidireta. Aquele filósofo toma os novos instrumentos da Democracia Semidireta. Pensa estar votando um plebiscito e é surpreendido com a aprovação de uma ditadura. Ele estremece!

Nesse "Jogo da História", mudança não significa avanço. Tudo que fora conquistado pode perder-se com um segundo de cochilo. Não há tese que 
conquiste uma escada de progresso em sentido único. Os degraus podem enganar. Contudo, a tese da "Democracia Processual" elaborada por Habermas parece ser o projeto mais bem formulado sobre uma Democracia possível.

\section{1 "DEMOCRACIA PROCESSUAL" E AS VARIÂNCIAS DO "JOGO DEMOCRÁTICO"}

Tão variável quanto os conceitos é a história da Democracia, mas há um ideal necessário que, mesmo de difícil conceituação, ao ser colocado em xeque todos correm para sua defesa: "O Estado de Direito é como a democracia, a liberdade e às vezes o próprio Direito: certas pessoas só o reconhecem e estimam depois de violados ou conculcados." (BONAVIDES, 2010, p.327). É isto que torna a Democracia, mesmo mutável, irrenunciável e essencial.

O exame da Democracia é, portanto, a análise de uma das facetas deste "jogo da vida", das regras do jogo e dos seus jogadores. Ocorre que o termo "Democracia", apesar de ter tido seu início na Grécia e Roma, recebeu variâncias alternadas, tendo como seu maior veículo de defesa no discurso político de legitimação do poder a Revolução Francesa em 1848: "Fue necesario esperar hasta 1848 para que en Francia la palabra democracia se impusiera realmente en el enguaje político." (ROSANVALLON, 2006, p.9).

A partir do momento revolucionário da Idade Moderna, Democracia corresponderá a uma concepção política de aproximação e controle entre comandantes e comandados. Com o século XIX e o movimento marxista e comunista a Democracia ganha ares de ideologia combatida e inaugura-se uma fase de inclusão dos direitos de povo soberano acima dos valores estatais. Isso veio a acentuar-se com a eclosão das duas Grandes Guerras Mundiais, as quais inauguraram o declínio do projeto democrático como concebido pela época liberal burguesa das revoluções do século XVIII: "Logo depois da Primeira Guerra Mundial, as democracias pareciam triunfar no mundo, definitivamente. [.... Às vésperas da Segunda Guerra Mundial, a democracia declinava em toda parte.” (DUVERGER, 1966, p.22,23). Só Neste âmbito começa a ser percebido o processo doloroso que a história tem enfrentado para qualquer conceituação sobre a Democracia.

Para avaliar a complexidade do "jogo democrático", a concepção da ideia de "jogo" em Heidegger auxilia na compreensão do que possa ser uma Democracia Processual:

[…] o jogar não é: 1 . Nenhuma sequência mecânica de ocorrências, mas um acontecimento livre, isto é, um acontecimento que está sempre ligado a regras. 2. Nesse acontecimento, o agir e o fazer não são essenciais. Antes de tudo decisivo no jogar é justamente o caráter específico de estado, 
o modo peculiar de encontrar-se-aí-disposto; 3 . Como o comportamento não é assim essencial ao jogar, o conjunto de regras também possui um outro caráter, a saber: as regras só se formam em meio ao jogar. A vinculação é uma vinculação livre em um sentido totalmente particular. O jogo se desenrola a cada vez somente em meio a um jogo, que não pode se desprender como um sistema de regras. É somente nesse seu desenrolar que o jogo surge pela primeira vez. [....] Nisso tudo reside, contudo: 4. As regras do jogo não são normas fixas, retiradas de um lugar qualquer, mas são variáveis no jogar e por meio ao jogar. Esse jogar praticamente cria para si mesmo, a cada vez, o espaço interior do qual ele pode se formar, o que significa, ao mesmo tempo transformar-se. (HEIDEGGER, 2009, p.332, 333). Grifo Nosso.

Definir a Democracia apenas como "regras do jogo" seria perder de vista o caráter sociológico impregnado neste termo. Habermas deixa clara a separação entre Estado de Direito e Democracia, afirmando que a Democracia não é meramente um ato jurídico, mas também político e sociológico. E o Estado de Direito é mais que um complexo de regras jurídicas que regulam o jogar, é um processo que deve ser regulado por uma razão consensual. Essa vinculação entre Direito e Democracia se torna mais relevante a partir da inclusão, pela teoria política, dos direitos humanos como extensão da soberania popular, afinal são eles que: "[....] fundamentam uma soberania das leis legítima a partir de si mesma." (HABERMAS, 2001, p.146).

O que este autor defende é a existência de uma "conexión interna" (HABERMAS, 2001, p.248) entre a Democracia e o Estado de Direito, que aqui estamos denominando "Democracia Substantiva", que não apenas contenta-se com as regras do jogo.

Esta conexão interna, entre Democracia e Estado de Direito, entre norma e valor, está relacionada com a práxis política de se buscar uma fundamentação democrática ao agir estatal - ao chamado Estado Democrático de Direito:

[....] esta conexión interna está profundamente anclada en las presuposiciones de nuestra praxis jurídica cotidiana. En el modo de validez proprio del derecho se abraza la facticidad de la aplicación estatal del derecho con la fuerza fundamentadora de legitimidad de un procedimiento con pretensión de racionalidad, ya que fundamenta la libertad. (HABERMAS, 2001, p.248).

Essa conexão entre Democracia e Estado de Direito está situada nas regras no jogo. Contudo, o jogo não se reduz às regras. Kant chega a utilizar "o paradigma dos náufragos" (MAUS, 2009, p.97) e a existência de apenas uma tábua flutuante para sobrevivência. Isso tudo para acentuar o paradoxo que há na possibilidade de violência não fora das regras do jogo, mas no jogo: "[.... a pena ameaçada pela lei [.... não pode (poderia) ser maior que a perda da vida." (MAUS, 2009 , p.97). Nesse sentido, as regras do jogo e o jogo teriam sua conexão interna 
perdida: "Em casos extremos, violência não pode ser proibida justamente por motivos racionais [....]. Violência não pode ser proibida, nem permitida."(MAUS, 2009, p.97).

Essa conexão interna entre as regras do jogo e os valores fez com que o Estado Democrático de Direito passasse a ter uma via de acesso para a transcendência do ideal da Idade Antiga (Democracia Direta), da Idade Média (Democracia Indireta Absolutista), e da Idade Moderna (Democracia Representativa com valores racionalistas absolutos, decorrente do mito da cientificidade advinda do Iluminismo).

A conexão de valores do movimento democrático às regras do jogo fez com que o Estado tivesse que ser ao mesmo tempo Democrático e jurídico garantindo a segurança jurídica, mas também a possibilidade de reavaliação de suas próprias normas. Democracia inserida no agir estatal é a cláusula de abertura do jogo, é a chave das imprecisões e, ao mesmo tempo, é o motivo de sua segurança.

"Democracia" é mais que um título, é um anseio que está sendo criado/recriado com uma intenção valorativa de progresso: "Concibo el orden no como la perpetuación de lo existente, sino como su transformación. No cualquier cambio, por supuesto." (LECHNER, 1998, p.16). Ou seja, teorizar sobre a Democracia é retirá-la do seu aspecto puramente teórico para a sua entrega e confronto com a realidade, modificando-a e sendo modificada por ela: isto é o que chamamos aqui, com base na teoria heideggeriana de "transcendência".

Assim como o homem, o modelo democrático não é um dado que se consubstancializou com uma positivação normativa, é um processo, um "pão diário":

A democracia é certamente um bem inestimável, mas o Estado de Direito é como o pão de cada dia, como água para beber e como ar para respirar, e o melhor da democracia é precisamente o fato de só ela estar apta a garantir o Estado de Direito. RADBRUCH, 1990 apud (KAUFMANN, 2004, p.441).

Segundo Paulo Bonavides, o princípio democrático se tornou, hodiernamente, um direito humano de quarta geração, o mais fundamental dos direitos políticos (BONAVIDES, 2010, p.523). Este seu reconhecimento histórico fez petrificar valores, que até podem ser modificados, mas que possuirão uma correspondência valorativa que deverão superar. Esse reconhecimento histórico do valor democrático é o que Paulo Bonavides denomina "Democracia substancial" (BONAVIDES, 2010, p.326) em contraposição com a "Democracia adjetiva" (BONAVIDES, 2010, p.531). Aquela sendo a Democracia dos valores humanos conquistados historicamente e a Democracia adjetiva um modelo camaleônico de uma forma de "Democraticismo" (KELSEN, 2000, p.103) que apenas usa o termo Democracia para justificar barbáries. Ou seja, o reconhecimento do con- 
teúdo histórico conquistado, a Democracia Substancial, está para além do uso indiscriminado do termo democrático sem nenhuma submissão aos conteúdos conquistados para a afirmação desse padrão popular.

Ocorre que a democracia utilizada apenas como adjetivo, como título frio de um jogo em que não se pesam as regras e não se identificam de forma clara os jogadores e a liberdade no jogo, é um uso leviano do termo que apenas serve como justificativa para conferir: "[...] legitimidade a todas as formas possíveis de convivência [....].” (BONAVIDES, 2010, p.522).

Esse uso da Democracia Adjetiva é absolutamente refratária de todo o avanço da humanidade, e malfere uma dimensão dos direitos humanos: a quarta. É neste degrau que se encontra o movimento democrático - da irrenunciabilidade de passos já conquistados: "O símbolo da Democracia parece ter assumido um valor tão universalmente reconhecido que a substância da democracia não pode ser abandonada sem a manutenção do símbolo." (KELSEN, 2000, p.140).

Se for um valor que parece ter alcançado um grau de fundamentalidade ao conceito do próprio Estado, há que se buscar uma teorização que garanta e auxilie uma efetivação da participação popular e uma das mais importantes teorias foi construída por Jürgen Habermas baseado em sua Teoria do Discurso: a "Democracia Processual.".

A Democracia Processual, para Habermas, não representa apenas uma forma em construção, mas sim uma maneira específica de ultrapassar os paradigmas liberais tanto da Democracia da Grécia, como de Roma, pois para o autor, nestas duas experiências históricas só houve a democracia individualista. Ele propõe uma revolução no pensamento jurídico:

[....] realizar uma refundação do direito sobre novos princípios: sobre uma ética da discussão, a única capaz de substituir o direito formal e abstrato que proviria da especulação dos modernos pelo direito processual e pragmático oriudno, no modo argumentativo, da opinião pública. (GOYARD-FABRE, 2003, p.321).

Essa nova concepção de Democracia torna mais relevante a legitimidade procedimental do envolvimento do discurso e das convenções do que a mera previsibilidade das "regras do jogo". Ela ensina que a Democracia Processual para ser popular deve implicar em uma:

[....] criticabilidade dos princípios jurídicos à luz de uma racionalidade discursiva abrangente, envolvendo questões jurídicas (de consistência), pragmáticas (de estabelecimento de fins e determinação dos meios adequados a alcançá-los), ético-políticas (de valores) e morais (de justiça), assim como questões concernentes ao compromisso equitativo. (NEVES, 2006, p.58). 


\subsection{A RelaÇão: Homem, Experiência e Visão de Mundo para Realização da Democracia Processual}

Visão e conceito de mundo, para Heidegger, são distintos. Conceito de mundo remete à ciência, à possibilidade de definir conceitos que apreendam as realidades distintas. Já a visão de mundo é a esfera filosófica do modo como se concebe a realidade - é uma concepção: "[....] não é nenhuma mera contemplação das coisas, tampouco uma soma do saber sobre elas; visão de mundo é sempre um tomada de posição[....]." (HEIDEGGER, 2009, p.249). Visão é, pois, sinônimo de opinião (HEIDEGGER, 2009, p.250).

Visão de mundo em Heidegger é algo que ultrapassa a conceituação científica de conceitos puros e se afina com o que Moncada denomina de interpretação do mundo sensível feita pela observação humana:

Esse mundo que o homem faz sentir do nada, é o mundo dos "sentidos" e "significações" valiosos por ele comunicados às coisas através do esforço prometeico da sua autorrealização, interpretando-as e iluminando-as com a sua própria luz sua autêntica existência, que não é só luz de razão, mas também luz da consciência moral. (MONCADA, 1995, p.346).

A democracia como fenômeno existencial pode ser enquadrada na nomenclatura de Heidegger como um ser-aí, um estar sendo. Porque ela é um produto do existir e este: "[....] não é obra feita, mas sim obra a fazer." (HEIDEGGER, 2009, p.346).

O homem é o elemento subjetivo do estabelecimento da definição democrática, ao lado de fatores objetivos que compõem e variam de acordo com as disposições históricas. Nesse sentido, enfatizar a percepção do homem no contexto democrático é atentar para a "responsabilidade do cidadão" sobre o desenrolar do jogo democrático. E esta participação humana para realização do jogo democrático deve ser máxima: "Sin embargo, para que ambas las partes - la liberalidad y la democracia - prosperen, es menester mucho más que el mínimo" (HÖFFE, 2007, p.10).

Se o elemento humano da democracia é um fator que determina as significações do mundo que empírica e sensitivamente percebem-se, é importante o desenvolvimento de ações que permitam um extravasamento da visão de mundo que o cerca.

Por isso, não adiantará pensar em um "avanço" da democracia apenas pela criação de institutos normativamente democráticos em esferas outras: por exemplo, a defesa da implantação do recall no Brasil como solução para os governos em frangalhos. Essa exemplificação dura é uma tentativa para asseverar que o homem é um conglomerado de fatores e o Estado de Direito, isto é, as regras do jogo não podem abarcar. 


\section{A "ÉTICA DISCURSIVA" E O "DIALOGUISMO": DA DEMOCRA- CIA DE SEGUIDORES À DEMOCRACIA DOS FEITORES}

A Democracia representativa, característica do Ocidente, não está sendo capaz de um agir pleno de sua ideologia. Democracia não pode significar transferência cega do poder: "Democracia significava o que a palavra designa literalmente: poder do demos, e não, como hoje, poder dos representantes do demos.” (BOBBIO, 2000, p.372). Há vários motivos da defasagem no modelo ideal de Democracia Representativa:

La forma de Estado predominante en Occidente - le democracia representativa - establece un vínculo entre legitimación democrática de todo el poder estatal y las responsabilidades claras en su ejercicio. No obstante, para contribuir hacer realidad el poder del pueblo que se requiere en una democracia. La democracia representativa se ve incluso solapadamente socavada por numerosos motivos. Por ejemplo, debido al gran poder de los partidos y de los medios masivos, y también de algunas asociaciones, sumado a la creciente vida propia de la política profesional, la realidad política se aleja del ideal de una democracia suficientemente representativa. (HÖFFE, 2007, p.101). Grifo nosso.

Ante o quadro de ingerência nociva ao modelo democrático o titular do poder, o povo, aparece no jogo apenas como metáfora:

"Povo" não deve funcionar como metáfora; o povo deve poder aparecer como sujeito político empírico. A concepção não necessita do povo" como expressão que não obriga a nada e cobra tudo; ela não necessita de nenhuma "vontade geral" que não deixasse verificar e identificar na política empírica, mas de um "povo" que possa, no plano das instituições, efetivamente entrar em cena como destinatário e agente de controle e de responsabilidade: eleição/ destituição do mandato por votação, bem como votação livre como componente democrático do cerne da Constituição. (MÜLLER, 2004, p.60).

Não há como negar que a conquista da possibilidade de eleger seus governantes foi um avanço na história da humanidade: "Só se pode falar apropriadamente de soberania do povo a partir do momento em que foi constituído o sufrágio universal [....]" (BOBBIO, 2000, p.379). Contudo, esta não é a última forma de concepção do poder democrático, pois se criou um povo que não joga, mas tão somente elege e segue os que, efetivamente, jogam e guiam os seus representados.

É possível falar em democracia do homem autodirigido, autorresponsável no Estado Democrático de Direito com o modelo de representação indireta? É esta a meta de parte da doutrina que tem já apontado para uma atuação 
mais enfática do homem no construir \reconstruir a realidade democrática. Atingir o que Kaufmann chama de o homem "autorresponsável" - é meta disposta pelo projeto democrático de transcendência que aqui se investiga:

A democracia, ao invés, exige o 'cidadão emancipado' capaz de decidir e agir de forma autorresponsável, mesmo se colocado em situações de risco. [....] $O$ cidadão plenamente emancipado está longe de existir como a democracia plena. Nenhum dos dois é um dado, eles são tarefas para as quais se tem constantemente de trabalhar. (KAUFMANN, 2004, p.442). Grifo nosso.

Não estamos seguros com as regras, a história já nos mostrou regimes nazistas e fascistas que começaram com ideais democráticos e socialistas apenas nos nomes. Não estamos seguros com utopias ontológicas, o devir pressupõe o risco de jogar, o ultrapassar controlado pela luta da participação e ingerência nesse dia a dia do poder democrático, pois há um fato irrefutável: "A democracia suporta ter nas suas chefias personalidades medíocres, mas não resiste ao comportamento passivo do povo." (KAUFMANN, 2004, p.441). Por este motivo, a tese de Habermas de uma "Democracia Processual" vem a reacender a dívida dos modelos democráticos de proporcionar uma inserção do controle popular sobre os "representantes". A busca por esta inserção eficaz do povo é iniciada com o Dialoguismo.

\subsection{Dialoguismo e o Poder Democrático Consensual: um RETORNO À EFICÁCIA SOCIAL DAS NORMAS JURÍDICAS}

O poder popular é o símbolo que significa a teoria democrática. E poder é uma esfera de significantes querendo traduzir realidades, mas às vezes pode ser usado como "simbolização" e meio de mascarar verdades;

A simbolização enquanto tal é um requisito indispensável da formação do poder. [....] A simbolização é de uma possibilidade estabilizada, uma disposição para a autocatálise do sistema que pode tornar-se produtiva se surgem novas condições. (LUHMANN, 1992, p.28). Grifo nosso.

Nessa linha, o poder torna-se temerário, pois pode flamular uma bandeira que jamais corresponderá à sua atuação prática. Como conviver com a sombra de um modelo que comporta diversos conteúdos?

A proposta de Habermas está na acentuação da evolução da capacidade de inserção do diálogo na forma de exercício do poder. Para isso lança a sua "Teoria Comunicativa" com inspiração nas teses de Piaget e Kohlberg. Esta teoria assevera que os paradigmas da Revolução Francesa e Americanas que alavancaram o processo de luta pela Democracia estão chegando a um novo amadurecimento: a processualidade do poder. 
O jogo então deixa de ter como postulado o que Habermas chama de "Monologuismo" (GOYARD-FABRE, 2003, p.321) o poder entregue à representantes que teriam a partir daí uma autonomia de decisão incontrolável popularmente; para avançar para um novo paradigma: o "Dialoguismo", uma forma de inserção da necessidade de compreensão, recepção e aceitação por parte do povo dos atos de poder:

Portanto, o novo paradigma do direito que essa 'democracia processual' convoca pede que a discussão argumentada predomine sobre a decisão voluntária do poder. Substituir o monologuismo pelo dialoguismo ainda é insuficiente enquanto este último não se inscrever no registro da argumentação pública. (GOYARD-FABRE, 2003, p.324).

Essa ponte criada pela teoria de Habermas faz acender a tese de uma necessidade de vínculo entre a esfera normativa e a social. Contrariando a tese formalista de Hans Kelsen, na qual apenas a validade seria necessária para avaliação do que é ou não direito: “[....] a regra jurídica é válida até mesmo nos casos em que lhe falta "eficácia"” (KELSEN, 1998, p.42). Essa distanciação entre norma e realidade não é mais aceita.

Habermas propõe uma fusão entre a esfera normativa e a faticidade: "[....] uma espécie de validade que é equiparada coma força do fáctico [....]." (HABERMAS, 1992 apud NEVES, 2006, p. 54). Essa fusão só pode ser conseguida se a Democracia aprender o processo de difusão do poder com o agir comunicacional:

A razão processual exige uma prática de entendimento consensual, o que evita, pretende Habermas, não só o que ele considera como o momento dogmático que é uma teoria constitucional do Estado, mas também as aporias da metafísica ontológica ou axiológica e os impasses da filosofia do sujeito. (GOYARD-FABRE, 2003, p.324).

A Democracia não se resumiria ao estabelecimento de normas jurídicas válidas, mas sim a um processo racional de "Legitimação Processual" (NEVES, 2006, p.58) do exercício do poder democrático. E mais, não é necessária apenas a fusão destes âmbitos: "O direito reclama não apenas aceitação; ele demanda dos seus endereçados não apenas um reconhecimento fático, mas antes reivindica merecer o reconhecimento." (HABERMAS, 2001, p.144).

O "Jogo Democrático" teria como regra principal o estabelecimento de uma razão consensual e não de imposição. Este parâmetro garantiria a formação de uma Democracia de feitores. 


\section{Conclusão}

Na história narrada no início deste artigo o Jogo Democrático foi surpreendido com um referendo de uma ditadura, quando o mesmo foi intitulado como plebiscito. E esta parte da metáfora foi baseada no uso leviano do instituto do plebiscito efetuado em Portugal em 1933 para institucionalizar a ditadura salazarista. É por isso que aquela história narrada no início não termina. Enquanto houver o jogo da vida, lá estarão as regras do jogo e os diversos jogadores. Como já afirmado: mudança não significa, necessariamente, evolução.

Esse é o jogo. Tão paradoxal quanto o homem. Ora parece um modelo divino, sua "imagem e semelhança", ora a encarnação de todo o oposto. Por isso, a "Visão de Mundo" como opinião torna o objeto de investigação, a Democracia, um produto não absoluto, mas produzido pela fraqueza humana, em todas as suas nuances. Isso tudo para evitar que se impregne uma áurea absoluta nas regras do jogo que possa ferir expectativas.

O poder popular é um aviso: não imagine modelos estáticos, pois, como percebido pelo poeta, o homem é um misto de contentamento e intranquilidade imersos em sua fragilidade e limitação: "El poderoso elemento, el fuego de los cielos, la tranquilidad de los hombres, su vida en la naturaleza, su limitación y contentamiento,[....]." (Holderiin, S/D apud HEIDEGGER, 1958, p.142).

Eis a Democracia que buscamos: a transcendente - inalcançada e alcançada, no achar e perder-se do caminho histórico. A forma de simbolizar o poder como popular não nos é suficiente. É necessário ensarilhar as armas discursivas para combater os discursos quietistas desviantes, afinal: Democracia é um lutar pelas regras e contra as regras, uma transcendência do jogar quando a realidade exigir a ultrapassagem.

A forma de lutar pelo "Jogo Democrático" legítimo, segundo a doutrina de Habermas, passa pela evolução de uma Legitimidade e Democracia Processuais, baseadas na Ética do Discurso, na aproximação da faticidade com a normatividade, abandonando concepções formalistas como a de Hans Kelsen sobre a normatividade suficiente.

Essa discussão sobre o conteúdo e significado do termo "Democracia" não pode ser apreendida em um único fôlego, é um processo, antes de ser um conceito, tem elementos que se agregam paulatinamente. No conceito de Democracia está envolvido o homem e o poder, aquele como fonte deste. E as vicissitudes que daí surgem são as surpresas do jogo. Que ora merecem medo, ora aplausos. Mas em todo o tempo nos reclama atenção. 


\section{REFERÊNCIAS}

AMARAL, Roberto. A democracia participativa. In.: Eros Roberto Grau e Willis Santiago Guerra Filho (Org.). Direito Constitucional: estudos em homenagem a Paulo Bonavides. São Paulo: Malheiros, 2003.

BOBBIO, Norberto. Teoria geral da política: a filosofia política e as lições dos clássicos. Tradução Daniela Beccaccia Versiani. Rio de Janeiro: Elsevier, 2000.

. Liberalismo e democracia. Tradução Marco Aurélio Nogueira. São Paulo: Brasiliense, 2000.

BONAVIDES, Paulo. Teoria geral do estado. São Paulo: Malheiros, 2010.

DAHRENDORF, Ralf. Sociedad i libertad: hacia un análisis sociológico de la actualidade. Tradutor Jose Jimenez Blanco. 2. ed. Madrid: Editorial TECnos, 1971.

DUVERGER, Maurice. Os regimes políticos. Tradução de Geraldo Gerson de Souza. 2. ed. São Paulo: Difusão europeia do livro, 1966.

FERRAJOLI, Luigi. O estado de direito entre passado e futuro. In: ZOLO, Danilo; PIETRO, Costa (Org.). O Estado de direito: história, teoria, crítica. Trad. Carlo Alberto Dastoli. São Paulo: Martins Fontes, 2006.

GOYARD-FABRE, Simone. O que é Democracia? (A genealogia filosófica de uma grande aventura.). trad. Claudia Berlinder. São Paulo: Martins Fontes, 2003.

HABERMAS, Jürgen. La inclusión del otro: estudios de teoría política. Tradução Juan Carlos Velasco Arroyo e Gerard Vilar Roca. Barcelona: Paidós Básica, 1999.

HEIDEGGER, Martin. Introdução à filosofia. Tradução de Marco Antônio de Souza. 2. ed. São Paulo: WMF Martins Fontes, 2009.

de Cultura Económico, 1958.

Arte y poesía. Tradução Samuel Ramos. México: Fondo

HÖFFE, Otfried. Ciudadano económico, ciudadano del Estado, ciudadano del mundo: ética política en la era de la globalización. Tradução Carlos Díaz Rocca. Buenos Aires: Katz, 2007. 
. Justiça Política: fundamentação de uma filosofia crítica do direito e do estado. Tradução Ernildo Stein. 3. ed. São Paulo: Martins Fontes, 2005.

KAUFMANN, Arthur. Filosofia do direito. Tradução António Ulisses Cortês. Lisboa: Fundação Calouste Gulbenkian, 2004.

KELSEN, Hans. A democracia. 2. ed. Tradução Ivone Castilho Benedetti; Jefferson Luiz Camargo; Marcelo Brandão Cipolla; Vera Barkow. São Paulo: Martins Fontes, 2000

LECHNER, Norbert. Los patios interiores de la democracia: subjetividad y política. Santiago: Facso, 1998.

LUHMANN, Niklas. Poder. 2. ed. Tradução Martine Creusot de Rezende Martins. Brasília: Universidade de Brasília Edunb, 1992.

MAUS, Ingeborg. Direito e política: teoria da democracia. Tradução Elisete Antoniuk. Belo Horizonte; Del Rey, 2009.

MONCADA, L. Cabral. Filosofia do direito e do estado. Coimbra: Coimbra, 1995.

MÜLLER, Friedrich. Fragmento (sobre) o poder constituinte do povo. Tradução Peter Naumann. São Paulo: Revista dos Tribunais, 2004.

. Quem é o povo?: a questão fundamental da democracia. Tradução Peter Naumann. São Paulo: Max Limonad, 1998.

NEVES, Marcelo. Entre Têmis e Leviatã: uma relação difícil. (O Estado Democrático de Direito a partir e além de Luhmann e Habermas. São Paulo: Martins Fontes, 2006.

RADBRUCH, Gustav. Filosofia do direito. Tradução Marlene Holzhausen. São Paulo: Martins Fontes, 2004.

ROUSSEAU, Jean-Jacques. Do contrato social; ensaio sobre a origem das linguas; discurso sobre a origem e os fundamentos da desigualdade entre os homens: Jean-Jacques Rousseau. Tradução: Lourdes Santos Machado. 5.ed. São Paulo: Nova Cultural, 1991. V-XXI, 320 p. (Os Pensadores). 
ROSANVALLON, Pierre. La historia de La palabra "democracia" en La época moderna. In: Estudos Políticos. N.28. Instituto de Estudios Políticos: Colombia. Jan- Jun. 2006.

TAPIAS, José Antonio Perez. Del bienestar a la justicia: aportaciones para una ciudadanía intercultural. Madrid: Trotta, 2007.

ZAGREBELSKY, Gustavo. Historia y constitución. Tradução Miguel Carbonell. Editora Minima Trota. Madri: Marfa Impresión, 1996.

\section{DEMOCRACY ARGUMENTS AS ESSENTIAL REQUIREMENT OF COMPLIANCE WITH THE DEMOCRATIC IDEAL}

Abstract: This article is meant to examine the perspective of Jurgen Habermas on Democracy Procedure, the creation of new paradigms for a reason and the necessary consensus binding law, the "rules of game" in social reality, the "Democratic Match."

Keywords: Democracy. Power. "Game Rules". Heidegger. Habermas.

Data de recebimento: nov/2010 - Data de aprovação: jan/2011 